\title{
Determination of plasma salbutamol concentrations after nebulization in a pediatric emergency department
}

\author{
Eloni T. Rotta, ${ }^{1}$ Sérgio L. Amantéa, ${ }^{2}$ Pedro E. Froehlich, ${ }^{3}$ Adriana Becker ${ }^{4}$
}

\begin{abstract}
Objectives: To partially validate the methodology for determining salbutamol in human plasma through high-efficiency liquid chromatography and fluorescence detection. To analyze plasma salbutamol concentrations in a group of pediatric patients with indication for nebulization in the emergency room.

Method: Analytical, prospective cross-sectional case series. Fifteen patients aged 12 to 37 months with a diagnosis of acute asthma crisis were selected at the Pediatric Emergency Service at Hospital da Criança Santo Antônio - Complexo Hospitalar Santa Casa, Porto Alegre, Brazil. The patients were treated following the unit's routine for the management of acute asthma crises: nebulization with salbutamol (flow rate of $6-8 \mathrm{~L} / \mathrm{min}$ ) $(0.15 \mathrm{mg} / \mathrm{kg}$ ) suspended in $4 \mathrm{~mL}$ of $0.9 \%$ saline solution. Nebulization was administered sequentially, three times, at 20 minute intervals. All patients were given prednisolone orally $(1 \mathrm{mg} / \mathrm{kg}$ ) concurrently with the nebulizations.

Results: Plasma concentrations exhibited great variability in acute asthma crisis patients given three nebulizations of salbutamol $(0.15 \mathrm{mg} / \mathrm{kg}$ ). The mean level in plasma was $12.09 \pm 10.8 \mathrm{ng} / \mathrm{mL}$, with a median of $8.9 \mathrm{ng} / \mathrm{mL}$ (IQ25-75\% 2.75-17.65). The sample's coefficient of variation was $92.4 \%$.

Conclusions: Post-inhalation plasma salbutamol concentrations exhibit great variation in the pediatric population, as seen in other studies. The possible causes and implications of this finding remain the subject of disagreements and of further assessments.
\end{abstract}

J Pediatr (Rio J). 2007;83(5):481-484: Plasma concentration, salbutamol.

\section{Introduction}

Short-acting $\beta_{2}$-agonists, administered via inhalation, are the treatment of choice for acute asthma crises in the pediatric population. This option is justified not only by their clinical efficacy, but also by the lower rate of occurrence of adverse effects, when compared with other administration routes. ${ }^{1-3}$ Salbutamol is the $\beta_{2}$-agonist used with greatest frequency for treating acute asthma crises (out of terbutaline, salbutamol and fenoterol). ${ }^{4}$ Although salbutamol's pharmacodynamics have been well-documented, information on its pharmacokinetics is limited, due to the difficulty involved in measuring the drug when at therapeutic concentrations. As a result, few studies have been designed to attempt to determine plasma concentrations of the drug, particularly in children. ${ }^{5}$

Currently, liquid chromatography is one of the methods most often used for the analysis of drugs in biological matrices. Variations to the technique have been described, in an attempt to establish a standard for assaying salbutamol in plasma and urine, ${ }^{1,2}$ however, the detection limit of some of these methods is inadequate, primarily at lower plasma concentrations $(\mathrm{ng} / \mathrm{mL})$, as is the case with salbutamol administered via inhalation. ${ }^{1}$

The objective of this study is to describe the partial validation process of a high-performance liquid chromatography

1. Farmacêutica, Serviço de Farmácia, Hospital São Lucas, Pontifícia Universidade Católica do Rio Grande do Sul (PUCRS), Porto Alegre, RS, Brasil.

2. Professor adjunto, Departamento de Pediatria, Fundação Faculdade Federal de Ciências Médicas de Porto Alegre (FFFCMPA), Porto Alegre, RS, Brasil. Chefe, Serviço de Emergência Pediátrica, Hospital da Criança Santo Antônio (HCSA), Complexo Hospitalar Santa Casa, Porto Alegre, RS, Brasil.

3. Professor associado, Faculdade de Farmácia, Universidade Federal do Rio Grande do Sul (UFRGS), Porto Alegre, RS, Brasil.

4. Médica assistente, Serviço de Emergência Pediátrica, HCSA, Complexo Hospitalar Santa Casa, Porto Alegre, RS, Brasil.

Suggested citation: Rotta ET, Amantéa SL, Froehlich PE, Becker A. Determination of plasma salbutamol concentrations after nebulization in a Pediatric Emergency Department. J Pediatr (Rio J). 2007;83(5):481-484.

Manuscript received Apr 04 2007, accepted for publication May 142007.

doi 10.2223/JPED.1689 
A

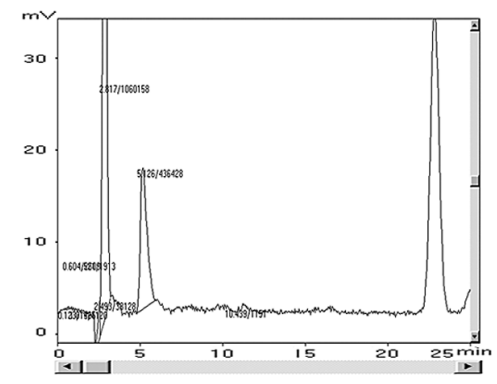

B

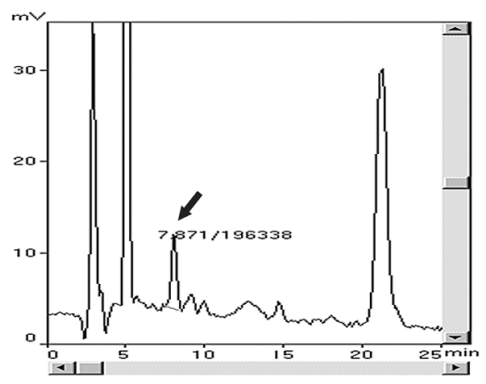

C

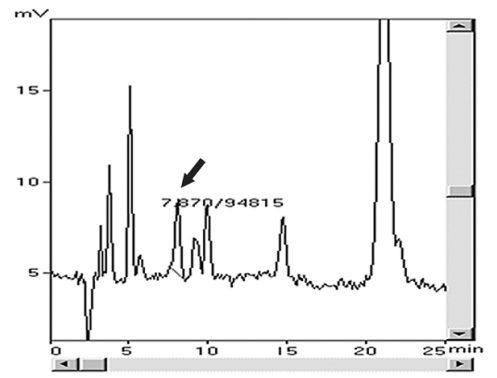

Figure 1 - Chromatograms obtained from plasma: A) blank; B) standard sample containing $25 \mathrm{ng} / \mathrm{mL}$ of salbutamol; C) sample of plasma from patient

method (HPLC) with fluorescence detection, proposed by Hutchings et al., ${ }^{6}$ and adapted for local conditions. Based on these bioanalytical measures, we attempted to determine plasma salbutamol concentration in a series of patients with therapeutic indications for that medication in inhaled form.

\section{Methods}

\section{Partial validation of the methodology (HPLC with fluorescence detection)}

\section{Equipment and reagents}

Liquid chromatograph, Shimadzu brand (LC-10AD pump, Phenomenex-Gemini-C18-5 $\mu-150 \times 4.60 \mathrm{~mm}$ analytical column, C18 pre-column, Shimadzu-RF551 fluorimetric detector) and a Shimadzu CBM 10A data processor. Mobile phase (MP) comprising $3 \%$ acetonitrile, $0.5 \%$ orthophosphoric acid at $85 \%$ and $96.5 \%$ ultrapure water.

Salbutamol was detected with excitation at $275 \mathrm{~nm}$ and emission at $309 \mathrm{~nm}$ (flow rate of $0.8 \mathrm{~mL} / \mathrm{min}$ ).

The method was partially validated using a validated secondary standard salbutamol. For extraction we employed: Di(2-ethylhexyl)phosphate (DEHP) (Sigma) and chloroform (Merck). The phosphate buffer $(\mathrm{pH}=7.2)$ was used at a strength of $0.42 \mathrm{M}$. The MP employed acetonitrile (Vetec) and orthophosphoric acid (Merck).

\section{Calibration curve}

In order to partially validate the technique it was necessary to define the calibration curve, with a range of different dilutions of the pharmaceutical added to human plasma (standard sample). The concentrations employed to define the curve were: $3.125,6.25,12.5,25$ and $50 \mathrm{ng} / \mathrm{mL}$.

In order to develop the analytical phase, salbutamol was extracted by an ion-pairing process. This consists of placing each standard sample in different centrifuge tubes containing $200 \mu \mathrm{L}$ of phosphate buffer $(\mathrm{pH}=7.2)$, extracted by the addition of $6 \mathrm{~mL}$ of a DEHP solution ( $0.1 \mathrm{M}$ in chloroform), by means of agitation ( 2 minutes in vortex) and centrifuging for
10 minutes. The chloroform phases were then collected from these tubes and transferred to other centrifuge tubes containing $500 \mu \mathrm{L}$ of hydrochloric acid at $0.5 \mathrm{M}$. The salbutamol was extracted by agitation ( 2 minutes in vortex) and centrifuged for 5 minutes. The acid phase was collected and a $50 \mu \mathrm{L}$ aliquot injected into the HPLC for determination of the salbutamol.

\section{Partial validation of the methodology}

The objective of analytical validation is to demonstrate that a method is appropriate for quantitative determination of a pharmaceutical or other substance. ${ }^{7,8}$ The changes made to the original technique were basically related to the chromatographic system (the model of the apparatus and the analytical column, flow rate, MP and the excitation and emission intervals of the detection system).

In order to partially validate the bioanalytical method, its characteristics of selectivity, linearity, accuracy and precision were determined. 7,8

The salbutamol was isolated from plasma with a retention time of 7.8 minutes and, at this interval, did not suffer interference from other peaks present in the control plasma (Figure 1). This technique provides evidence of the method's selectivity.

The method's linearity was demonstrated by constructing a calibration curve from concentrations in the interval 3.125 to $50 \mathrm{ng} / \mathrm{mL}$. The curve provided a graph of area vs. concentration, with the respective equations for straight line and coefficient of determination $\left(R^{2}\right)$, and also for their slopes and intercepts.

The values for $\mathrm{R}^{2}$ obtained were greater than or equal to 0.98 , indicating linearity between the ratio of the are of salbutamol and its theoretical concentration. ${ }^{7,8}$

The linearity of the analytical method was confirmed by linear regression by means of the ANOVA statistical method. The results provide evidence that there was no significant deviation from linearity $(p<0.05)$. 
Precision was assessed in terms of the repeatability (interday precision) and reproducibility (intraday precision) of the method, employing two samples defined as quality control at concentrations of 7.5 and $20 \mathrm{ng} / \mathrm{mL}$. The relative standard deviations (SD) that characterize the method do not exceed $15 \% .^{7,8}$ Accuracy at these concentrations was assessed in terms of the relationship between the mean assayed concentrations and their corresponding theoretical concentrations. Legislation defines that the variation between the true and theoretical values of the samples should be around $15 \%$. At a concentration of $7.5 \mathrm{ng} / \mathrm{mL}$, the range of variation observed was from 85.4 to $113.4 \%$ and at a concentration of $20 \mathrm{ng} / \mathrm{mL}$ it was 104.5 to $114.6 \%$, demonstrating the accuracy of the method. 7,8

\section{Study design}

The study was defined as a cross-sectional, analytical, prospective case series study. Fifteen patients were selected consecutively, between February and May of 2006, in the age range from 12 to 37 months, with a diagnosis of acute asthma crisis, seen at the Pediatric Emergency Service at the Santo Antônio Children's hospital, Complexo Hospitalar Santa Casa, Porto Alegre, Brazil. The clinical diagnoses were made by the medical team at the unit, with no researcher involvement.

Patients were treated according to the unit's routine for managing acute asthma crises: nebulization (flow rate of 6-8 $\mathrm{L} / \mathrm{min})$ with salbutamol $(0.15 \mathrm{mg} / \mathrm{kg})$ suspended in $4 \mathrm{~mL}$ of $0.9 \%$ saline solution. Nebulization was administered sequentially, three times, at 20 minute intervals. All patients were given prednisolone orally $(1 \mathrm{mg} / \mathrm{kg}$ ) concurrently with the nebulizations.

Patients were excluded from the sample if they had been given any other type of $\beta 2$-agonist during the preceding 12 hours.

Ten minutes after completion of the treatment a blood sample was taken from each patient for salbutamol determination. The material was immediately sent to the laboratory, its plasma separated in a centrifuge, and the material stored and frozen at $-80^{\circ} \mathrm{C}$ for later analysis.

All parents and/or guardians signed an informed consent form, and the study was approved by the Research Ethics Committee and at the institution ( $n^{\circ} 763 / 03$ ).

The results obtained were expressed in terms of means and their respective standard deviations and in asymmetrical cases by median and interquartile range $25-75 \%$ (IQ25$75 \%$ ). The coefficient of variation (CV) of the sample was calculated from mean and standard deviation. A CV greater than $30 \%$ would characterize the sample as being overly dispersed. ${ }^{9}$

\section{Results}

The mean age of the 15 patients was $22.4 \pm 6.8$ months, with median of 21 months (IQ25-75\% 19-25).

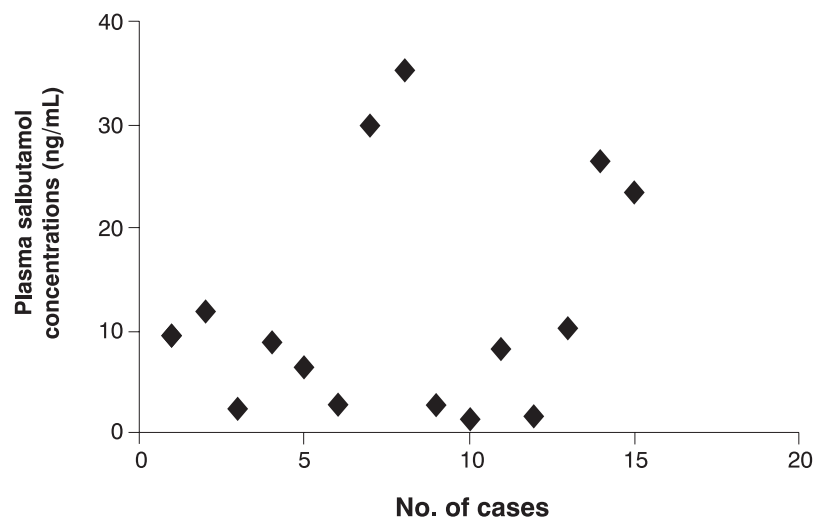

Figure 2 - Plasma salbutamol concentrations after initial treatment for asthmatic crisis

Figure 2 illustrates the distribution of salbutamol concentrations $(\mathrm{ng} / \mathrm{mL})$ observed in our series. The mean plasma level was $12.09 \pm 10.8 \mathrm{ng} / \mathrm{mL}$, with a standard deviation of 11.18 and a median of $8.9 \mathrm{ng} / \mathrm{mL}$ (IQ25-75\% 2.75-17.65).

Analysis of the Pearson's CV (92.4\%) revealed that plasma salbutamol level measurements were strongly dispersed. ${ }^{9,10}$

\section{Discussion}

The results of partial validation demonstrated that bioanalytical specifications were met and that the method can be used with safety for quantifying low concentrations of salbutamol in human plasma. Other methodologies have been described that involve modifications to the extraction process. ${ }^{11}$ The absence of interfering peaks in our sample meant that such alterations were not justified. The rigid eligibility criteria that we established, including the exclusion of other medications, may have contributed to this finding.

When we analyzed the post-nebulization concentrations obtained, we observed large degree of individual variation, with concentrations oscillating between 1.6 and $35.3 \mathrm{ng} / \mathrm{mL}$, with an elevated CV. This fact is extremely important since none of the patients selected had been given any other

$\beta_{2}$-agonist for at least 12 hours and had been given the same dosage of salbutamol, adjusted for body weight.

Favorable clinical responses have been described to salbutamol concentrations oscillating from 20 to $40 \mathrm{ng} / \mathrm{mL} .{ }^{12}$ However, varying plasma concentrations have been described, depending on the doses administered, with equally effective results. Using doses considered to be standard ( 0.15 $\mathrm{mg} / \mathrm{kg}$ administered at 20-minute intervals), Schuh et al. ${ }^{13}$ found concentrations of $4.4-16 \mathrm{ng} / \mathrm{mL}$ (mean of $9.4 \mathrm{ng} / \mathrm{mL}$ ), whereas as higher doses resulted in concentrations of 8.9-40 $\mathrm{ng} / \mathrm{mL}$ (mean of $24 \mathrm{ng} / \mathrm{mL}$ ). It is worth pointing out that their patients were older (5-17 years), which adds a potential confounding factor when comparing findings. 
As a result of such variation, it is possible to infer that other factors also interfere in plasma concentrations of inhaled salbutamol in the pediatric population. Our population produced data with large variability, with a median of 8.9 (IQ25-75\% $2.75-17.65 \mathrm{ng} / \mathrm{mL}$ ). This finding may be explained by data that indicate poor tolerance and greater technical difficulties when administering inhaled medication (nebulization) to young patients. ${ }^{14,15}$ The small sample size did not allow us to individually identify factors that could be related to the variability observed, which constitutes a limitation to the study.

Post-inhalation plasma salbutamol concentrations exhibit great dispersion within the pediatric population, as shown in other studies. The possible causes and implications related to this finding continue to be the subject of disagreement and are worthy of further investigations aimed at better understanding the pharmacokinetics of this medication when administered via inhalation.

\section{References}

1. Grupta RN, Fuller HD, Dolovich MB. Optimization of a column liquid chromatographic procedure for the determination of plasma salbutamol concentration. J Chromatogr B Biomed Appl. 1994;654:205-11.

2. Le Roux AM, Wium CA, Joubert JR, Van Jaarsveld PP. Evaluation of a high-performance thin-layer chromatographic technique for the determination of salbutamol serum levels in clinical trials. J Chromatogr. 1992;581:306-9.

3. Amantea SL, Sanchez I, Piva JP, Garcia PC. Controvérsias no manejo farmacológico da asma aguda infantil. J Pediatr (Rio J). 2002;78 Supl 2:S151-60.

4. Global Iniciative for Asthma (GINA). Global strategy for asthma management and prevention. Bethesda (MD): National Institutes of Health. 2002. http://www.ginasthma.com. Access: $07 / 12 / 2006$.

5. Tan YK, Soldin SJ. Determination of salbutamol in human serum by reversed-phase high performance liquid chromatography with amperometric detection. J Chromatogr. 1984;311:311-7.
6. Hutchings MJ, Paull JD, Morgan DJ. Determination of salbutamol in plasma by high-performance liquid chromatography with fluorescence detection. J Chromatogr. 1983; 277:423-6.

7. Brasil. Resolução - RE no 899, de 29 de maio de 2003. Dispõe sobre a validação de métodos analíticos. Brasília: Diário Oficial da República Federativa do Brasil; 02 jun 2003.

8. The International Conference on Harmonisation of Technical Requirements for Registration of Pharmaceuticals for Human Use (ICH) (Q2-R1). Text on validation of analytical procedures methodology. October 1994. http://www.ich.org. Access:17/ $06 / 2004$.

9. Datalyzer Spectrum. Coeficiente de variação. http:// www.datalyzer.com.br.Access: 04/05/2007.

10. Callegari-Jacques SM. Bioestatística: princípios e aplicações. Porto Alegre: Artmed; 2003.

11. Koh YM, Saleh MI, Tan SC. Selective extraction of salbutamol from human plasma with the use of phenylboronic acid. J Chromatogr A. 2003;987:257-67.

12. Browne GJ, Penna AS, Phung X, Soo M. Randomised trial of intravenous salbutamol in early management of acute severe asthma in children. Lancet. 1997;349:301-5.

13. Schuh S, Reider MJ, Canny G, Pender E, Forbes T, Tan YK, et al. Nebulized albuterol in acute childhood asthma: comparison of two doses. Pediatrics. 1990;86:509-13.

14. Ploin D, Chapuis FR, Stamm D, Robert J, David L, Chatelain PG, et al. High-dose albuterol by metered-dose inhaler plus a spacer device versus nebulization in preschool children with recurrent wheezing: a double-blind, randomized equivalence trial. Pediatrics. 2000;106:311-31.

15. Chong Neto HJ, Chong-Silva DC, Marani DM, Kuroda F, Olandosky M, Noronha L. Diferentes dispositivos inalatórios na crise aguda de asma: um estudo randomizado, duplo-cego e controlado com placebo. J Pediatr (Rio J). 2005;81:298-304.

Correspondence:

Sérgio L. Amantéa

Avenida Iguaçu, 463/503

CEP 90470-430 - Porto Alegre, RS - Brazil

Tel.: +55 (51) 3334.0146

E-mail: samantea@terra.com.br 